\title{
Shear strengthening of reinforced concrete beams strengthened using embedded through section steel bars
}

\author{
Matteo Breveglieri ${ }^{a, *}$, Alessandra Aprile ${ }^{a}$, Joaquim A.O. Barros ${ }^{b}$ \\ ${ }^{a}$ Dep. of Eng., University of Ferrara, 44121 Ferrara, Italy \\ ' ISISE, Dep. of Civil Eng., Univ. of Minho, Azurém, 4810-058 Guimarães, Portugal
}

\section{A R T I C L E I N F O}

\section{Article history:}

Received 22 May 2014

Revised 12 September 2014

Accepted 15 September 2014

\section{Keywords:}

Shear strengthening

Reinforced concrete beams

ETS steel bars

ETS technique

\begin{abstract}
A B S T R A C T
A new shear strengthening technique, designated as embedded through section (ETS), has been developed to retrofit existing reinforced concrete (RC) elements. This technique calls for holes to be drilled through the beam section; then bars of steel or FRP materials are introduced into these holes and bonded with adhesives to the surrounding concrete. When concrete cover has not the bond and strength requisites to guarantee a strengthening effectiveness for the Externally Bonded and Near Surface Mounted techniques, ETS strategy can be a competitive alternative since it mobilizes the beam's concrete core which is, generally, free of damage. To explore the potentialities of the ETS technique for the shear strengthening of RC beams, an experimental program was carried out, composed of RC T-cross section beams shear strengthened by using steel bars. The influence on the shear strengthening efficiency of the inclination and shear strengthening ratio of ETS configurations was evaluated; the study also examined the interaction of ETS bars and existing steel stirrups. An increase of shear capacity up to $109 \%$ and $136 \%$ in the beams with and without internal stirrups, respectively, was obtained. Inclined ETS bars provided higher increase of shear resistance than vertical ones.
\end{abstract}

(c) 2014 Elsevier Ltd. All rights reserved.

\section{Introduction}

Reinforced concrete beams need to be strengthened when they are insufficiently reinforced in shear and become subjected to higher loads, or when their shear capacities fall below their flexural capacity after flexural strengthening. Shear failure should be avoided because of its brittle and unpredictable nature. The relatively recent approaches for shear strengthening of RC beams made use of composites materials [1]. Competitive strengthening solutions using materials like carbon or glass fiber reinforced polymers (CFRP or GFRP) can be developed due to the high strength-to weight ratio, high durability (not corrodible), electromagnetic neutrality, ease of handling, rapid execution with low labor costs and low impact on architectural and aesthetic appearance. The most popular techniques based on the use of FRP reinforcements are the Externally Bonded Reinforcement (EBR) and the Near Surface Mounted (NSM). According to the EBR technique, sheets or laminates of carbon fiber reinforced polymers (CFRP) are bonded on the faces of the elements to be strengthened. In case of the NSM technique, CFRP laminates or bars are installed into slit/grooves

\footnotetext{
* Corresponding author.

E-mail addresses: matteo.breveglieri@unife.it (M. Breveglieri), alessandra. aprile@unife.it (A. Aprile), barros@civil.uminho.pt (J.A.O. Barros).
}

sawed into the beams' concrete cover and bonded to the concrete substrate by polymer adhesive. Due to the confinement provided by the surrounding concrete and the higher laminate-concrete bond surface [2-5], the available experimental research showed that NSM is more effective than EBR for both the flexural [3,6-9] and shear strengthening [10-15]. Other concerns regarding the use of EBR, apart from the relatively high cost of the FRP systems, are the susceptibility to fire and acts of vandalism, as well as the longer time needed to prepare the beam zones for the FRP bond. Maximum efficiency using composites material is obtained when the strengthening system is able to exploit its full tensional strain. Both EBR and NSM techniques rely on the stress transfer capacity between FRP and the concrete substrate. However, the latter is usually the most damaged part of the RC elements. Most of the experimental tests showed that the strengthened elements fail by debonding in EBR shear strengthening configurations. When using NSM technique the current failure modes are concrete fracture, followed by debond of the FRP systems. When the percentage of strengthening NSMreinforcement is relatively high, the concrete cover including the FRP reinforcement has the tendency to detach due to the reasons explained elsewhere [16]. By applying the NSM technique, the full tensile capacity of the CFRP reinforcements can only be attained when these reinforcements are surrounded by relatively high strength concrete and bond transference length is assured [13]. 
A new strengthening technique, designated as Embedded Through-Section (ETS), has recently been investigated for the shear strengthening of RC beams $[17,18]$. According to this technique, steel or FRP bars are inserted into holes bored through the cross section and bonded with an epoxy adhesive. This technique can be more effective for the shear strengthening due to the higher confinement provided by the concrete surrounding the bars, and the larger concrete fracture surface that is mobilized during the pullout process applied to the ETS bars crossing the shear crack. The ETS technique can also be extended for the punching shear strengthening of concrete slabs $[19,20]$. Significant increase of shear capacity has been pointed out by Valerio et al. [17,21] who investigated the use of the ETS technique for the shear strengthening of RC existing bridges, performed pullout tests for assessing the strengthening effectiveness of adhesive materials, and different embedment lengths for the ETS bars. The shear stress transfer mechanisms developed in an ETS bar were studied by Barros et al. [22] using similar specimens to the ones tested by Mattock and Hawkins [23] for traditional embedded steel bars. In this context, direct shear tests were executed with the purpose of capturing the main features of FRP/steel ETS bars as they contribute to the shear resistance, and to providing data for a rational decision about the most effective bars and adhesives for this type of application [22]. From the results, a significant increase in shear strength was obtained with a relatively low shear reinforcement ratio, and it was verified that steel bars were very effective for this purpose. Chaallal et al. [18] carried out tests to assess the effectiveness of the ETS technique using vertical CFRP bars by comparing the performance of the ETS, EBR and NSM techniques on beams with different percentages of internal steel stirrups. It was demonstrated that the ETS technique provided the highest efficiency and was able to convert shear failure into a flexural failure. In the continuation of a comprehensive research project initiated by Barros et al. [22] on the ETS shear strengthening effectiveness, an experimental program was carried out by Barros and Dalfré [24] with RC beams shear strengthened with ETS steel bars. The variables examined in this experimental program were the width of the beam's web, the percentage and inclination of the ETS bars, the spacing of existing steel stirrups and their interaction with the strengthening bars. A significant increase of load carrying capacity was obtained (between $14 \%$ and $124 \%$ ), proving that the use of ETS steel bars can be a very effective and cost-competitive shear strengthening technique. The beams with the higher percentage of ETS bars failed in bending, despite the very high percentage of flexural reinforcement used. The present work aims to contribute to a deeper understanding of the shear mechanisms of ETS technique, and provide useful data for the establishment of design guidelines on the shear strengthening of RC beams using this technique. For this purpose a comprehensive experimental program with almost real size scale RC beams, designed to fail in shear, was conducted; the results describe deflection, strains in the relevant shear reinforcement and strengthening systems, as well as an analysis of failure modes. Furthermore, the applicability of existing guidelines for the prediction of the contribution of FRP systems for the shear strengthening of RC beams is also assessed. This experimental and analytical research is a step forward on the already existing information on the use of ETS technique for the shear strengthening of RC elements [17,18,24].

\section{Experimental program}

\subsection{Test series}

The geometry and the reinforcement arrangements of the ten $\mathrm{T}$ cross-section beams are shown in Fig. 1. The reinforcement systems were designed according to Eurocode 2 [25], considering the flange contribution, and using an high percentage of longitudinal reinforcement $\left(\rho_{s l}=2.79 \%\right.$ ). A high percentage of steel stirrups ( $\phi 8 @ 90 \mathrm{~mm}$ ) in the $L_{2}$ beam's span was applied for promoting the occurrence of shear failure in the shorter span $\left(L_{1}\right)$, the one shear strengthened with the adopted ETS configurations, see Fig. 1. The monitored beam span $\left(L_{1}=0.9 \mathrm{~m}\right)$ is 2.5 times the effective depth of the beam's cross section $\left(L_{1} / d=2.5\right)$. According to Collins and Mitchell [26], beyond this limit the arch effect is negligible. The differences between the tested beams are restricted to the shear reinforcement systems applied in the $L_{1}$ beam's span. The experimental program consisted of the following two series of beams: 0S-Series that did not have conventional steel stirrups; 2S-Series that has steel stirrups $\phi 6 @ 300 \mathrm{~mm}$, corresponding to a shear reinforcing ratio $\rho_{s w}=0.10 \%$. Each series has a reference beam without any applied strengthening (Figs. 1 and 2) and four beams with different ETS strengthening solutions (Fig. 3). The investigated parameters are the strengthening ratio $\left(\rho_{f w}\right)$ and inclination $\left(90^{\circ}, 45^{\circ}\right)$ of the ETS steel bars, as well as the influence of the percentage of existing steel stirrups. A $10 \mathrm{~mm}$ diameter $\left(d_{E T S}\right)$ bar was adopted as ETS strengthening. Table 1 reports the strengthening configurations, indicating the number of applied ETS bars, inclination $\left(\theta_{f w}\right)$, spacing $\left(s_{f w}\right)$, shear strengthening ratio $\left(\rho_{f w}\right)$, the percentage of steel stirrups $\left(\rho_{s w}\right)$ and total shear reinforcement $\left(\rho_{s w}+\rho_{f w}\right)$. Fig. 3 shows the strengthening configurations of the two tested series. In the design of the ETS configuration it was assumed that the ETS bars work like steel stirrups with the capacity of mobilizing the yield stress of the steel, and a perfect bond for the bars/adhesive/concrete was considered. As previously demonstrated by Barros and Dalfré [24], the effectiveness of the ETS bars is higher if they are placed in between existing stirrups. Following this approach, the arrangements indicated in Table 1 and Fig. 3 were adopted, leading to four different $\rho_{f w}$ values. The ETS strengthening ratio varied between $0.15 \%$ (ETS vertical bars spaced at $300 \mathrm{~mm}$ ) and $0.34 \%$ (ETS bars at $45^{\circ}$ and spaced at $180 \mathrm{~mm}$ ).

\subsection{Material properties}

The concrete average compressive strength $\left(f_{c m}\right)$ of the beams was evaluated at 28 days and at the age of the beams' tests (approximately 225 days) by executing compression tests with cylinder specimens of $150 \mathrm{~mm}$ diameter and $300 \mathrm{~mm}$ height
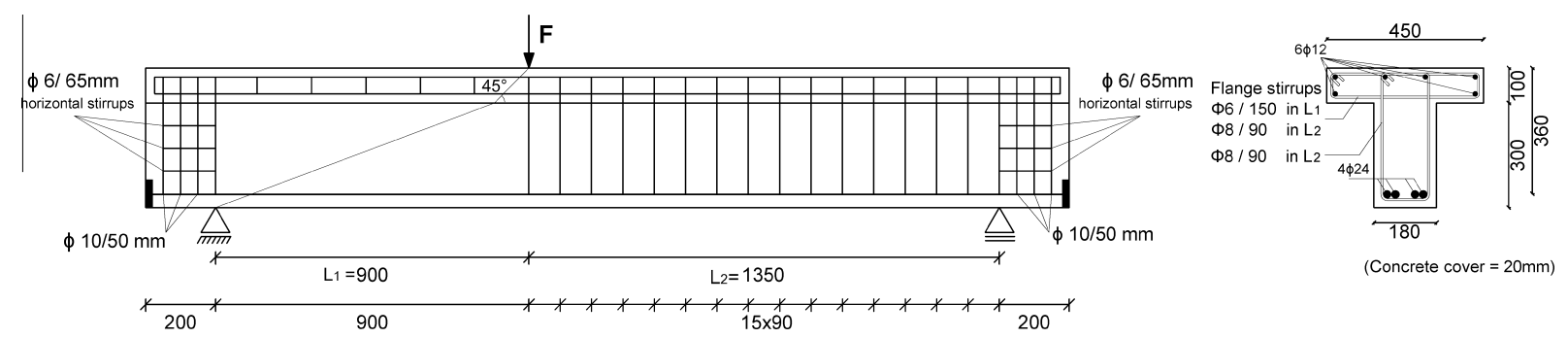

Fig. 1. Tested beams: geometry, steel reinforcements applied in all beams (dimensions in $\mathrm{mm}$ ). 


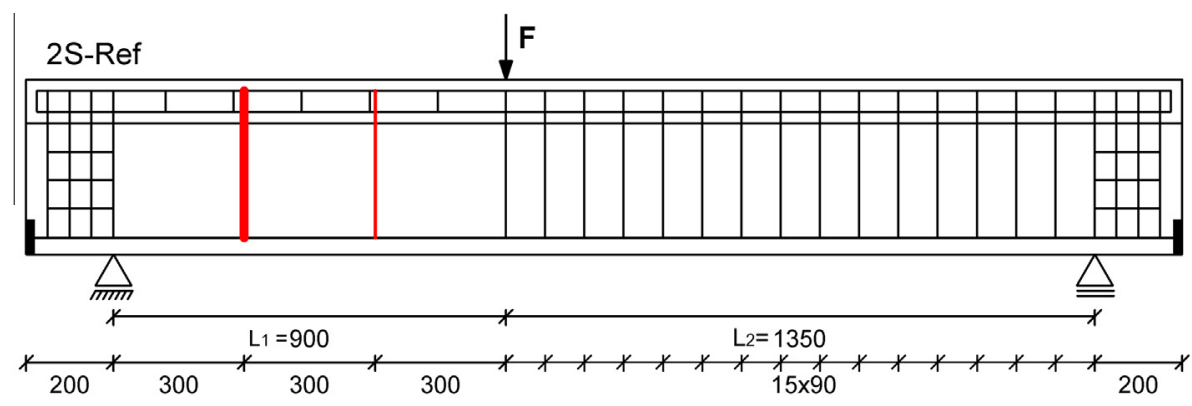

Fig. 2. Reference beam 2S-Ref (stirrups $\phi 6 / 300)$, (dimensions in mm).
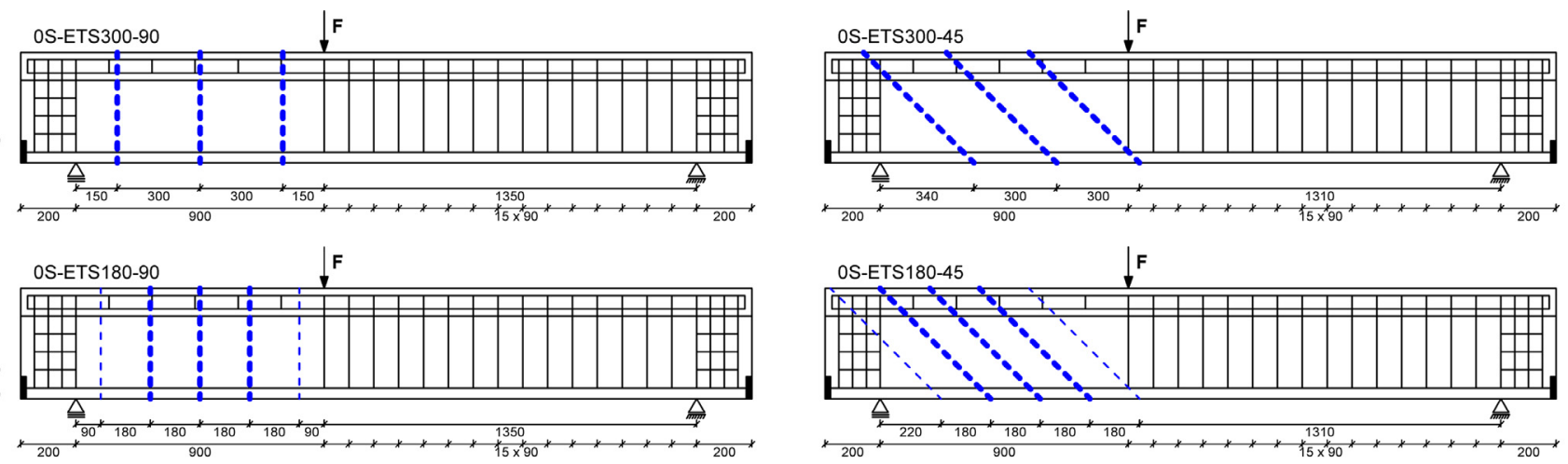

(a)
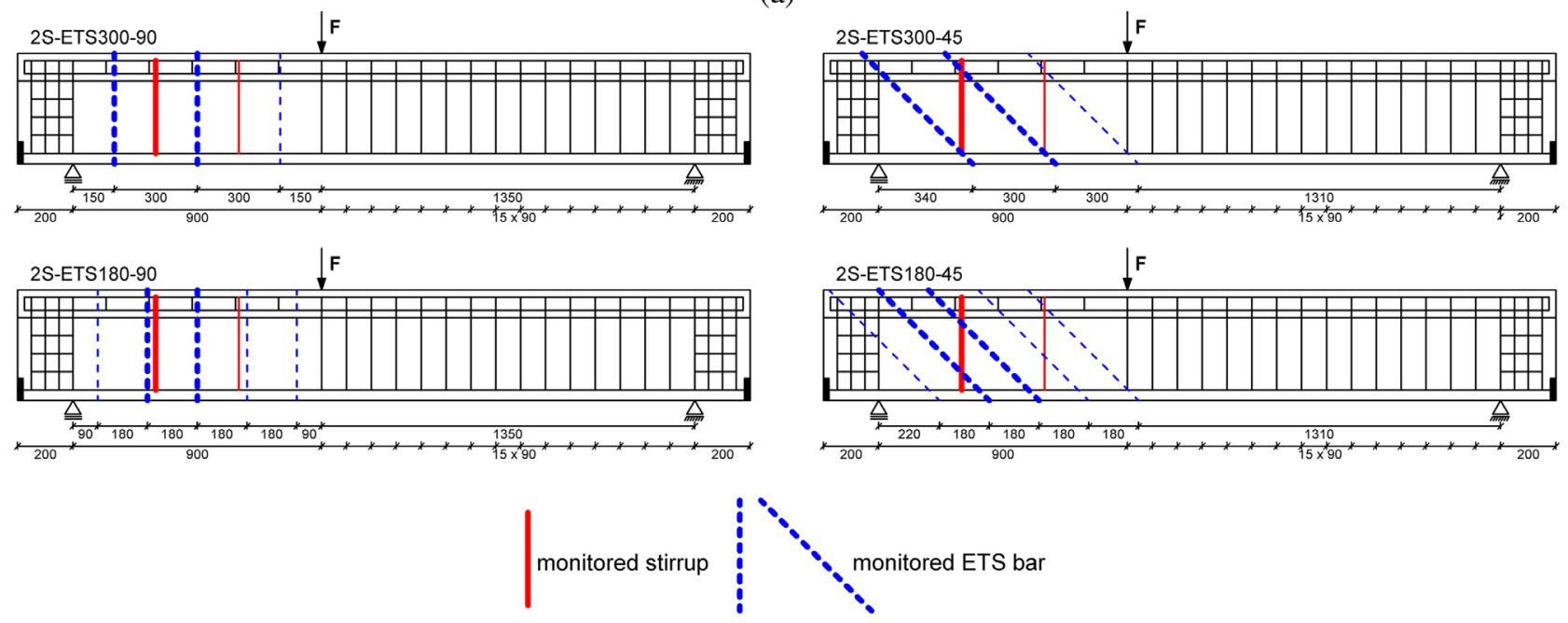

(b)
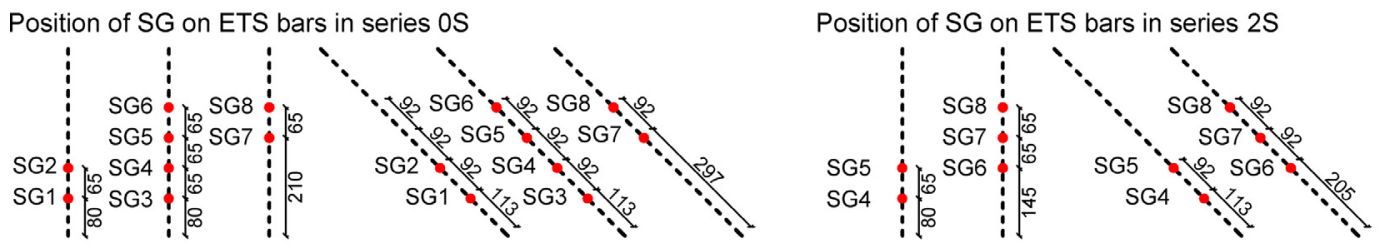

(c)

Position of SG on stirrups

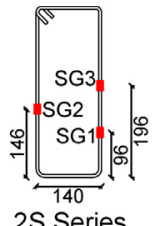

$2 S$ Series

Fig. 3. Strengthening configurations of series: (a) $0 S$; (b) $2 S$; (c) position of the strain gauges (dimensions in mm).

according to EN 206-1 [27]. At these dates the beams presented a $f_{c m}$ of 24.7 and $29.7 \mathrm{MPa}$, respectively. For the reinforcement of the beams, high bond steel bars of $6,10,8,12$, and $24 \mathrm{~mm}$ diameter were used. The steel class is B $450 \mathrm{C}\left(f_{y k}=450 \mathrm{MPa}\right)$ according to the Italian Construction Code [28]. The yield stress and tensile strength were obtained by means of uni-axial tensile tests performed according to recommendations of ISO 6892-1 [29]. For the steel bars of $6,8,10,12$ and $24 \mathrm{~mm}$ diameter it was obtained 
Table 1

ETS shear strengthening configurations of the tested beams.

\begin{tabular}{|c|c|c|c|c|c|c|c|}
\hline \multirow{2}{*}{$\begin{array}{l}\text { Number of bars } \\
d_{E T S}=10 \mathrm{~mm}\end{array}$} & \multirow{2}{*}{$\begin{array}{l}\text { Angle }\left[\theta_{f w}\right] \\
\left({ }^{\circ}\right)^{\mathrm{a}}\end{array}$} & \multirow{2}{*}{$\begin{array}{l}\text { ETS bar spacing }\left[s_{f w}\right] \\
(\mathrm{mm})\end{array}$} & \multirow{2}{*}{$\begin{array}{l}\text { ETS reinforcing ratio }\left[\rho_{f w}\right] \\
(\%)^{\mathrm{b}}\end{array}$} & \multicolumn{2}{|l|}{ OS-Ref ${ }^{\mathrm{C}}$} & \multicolumn{2}{|l|}{$2 S-\operatorname{Ref}^{\mathrm{d}}$} \\
\hline & & & & $\left(\rho_{s w}=0.0 \%\right)$ & $\rho_{s w}+\rho_{f w}(\%)$ & $\left(\rho_{s w}=0.10 \%\right)$ & $\rho_{s w}+\rho_{f w}(\%)$ \\
\hline 3 & 90 & 300 & 0.15 & OS-ETS300-90 & 0.15 & 2S-ETS300-90 & 0.25 \\
\hline 3 & 45 & 300 & 0.21 & OS-ETS300-45 & 0.21 & 2S-ETS300-45 & 0.31 \\
\hline 5 & 90 & 180 & 0.24 & OS-ETS180-90 & 0.24 & 2S-ETS180-90 & 0.35 \\
\hline 5 & 45 & 180 & 0.34 & OS-ETS180-45 & 0.34 & 2S-ETS180-45 & 0.45 \\
\hline
\end{tabular}

a Angle between the ETS bar and the beam's axis.

b The ETS percentage was obtained from Eq. (2).

c Series of beams without steel stirrups (0S-Series) (Fig. 1).

d Series of beams with two stirrups (2S-Series) (Fig. 2).

an average yield stress of 574, 505, 545, 527 and $598 \mathrm{MPa}$, respectively, and an average tensile strength of 667, 594, 649, 617 and $708 \mathrm{MPa}$. The adopted ETS steel bars were of the same class of the bars used for the flexural reinforcement and steel stirrups applied in the beams. To bond the ETS steel bars to the concrete substrate the Sikadur $32 \mathrm{~N}$ epoxy based adhesive was used. An average tensile strength of $20.7 \mathrm{MPa}$ and an elasticity modulus of $3.27 \mathrm{GPa}$ were determined by carrying out direct tensile tests according to the ISO 527-2 [30].

\subsection{Strengthening technique}

To simplify the drilling process and to avoid intersecting the longitudinal bars, the ETS strengthening process was executed with the beam's web turned upward. The main steps of the ETS strengthening technique are shown in Fig. 4. These steps are: (1) holes of $16 \mathrm{~mm}$ diameter were drilled through the center of the beams' web up to a depth of $20 \mathrm{~mm}$ from the top flange in order to maintain intact the concrete cover and avoid adhesive to flow through the bottom part of the hole (Fig. $4 \mathrm{a}$ and b); during the drilling process, the concrete dust was aspirated using a vacuum system; (2) the holes were cleaned by using an helicoidal steel brush capable of removing the particles from the walls of the hole, which were not eliminated by the vacuum system (Fig. 4c). The cleaning procedure was repeated until the dust was completely removed; (3) the epoxy resin, which was prepared according to the recommendations of the supplier, was slowly poured into the holes; (4) the steel bars, which were previously cut in the desired length and cleaned with acetone, were slowly introduced into the holes removing the resin in excess (Fig. 4d). To guarantee a proper curing of the adhesive, the beams were tested at least two weeks after the ETS application.

\subsection{Test set up and monitoring system}

Fig. 5 shows the position of the displacement transducers (LDTs) and force transducers for measuring the beam's deflection and applied/reaction forces, respectively. The LDTs were supported in a bar fixed at the beams supports' sections in order to register displacements only caused by the deflection of the beam. The displacement transducer TR1 was used to control the tests at a displacement rate of $0.01 \mathrm{~mm} / \mathrm{s}$ up to the failure of the beams. The applied load $(F)$ was measured using a force transducer of $\pm 750 \mathrm{kN}$ capacity and accuracy of $\pm 0.1 \%$. A second force transducer of $\pm 500 \mathrm{kN}$ capacity and $0.1 \%$ accuracy was placed under the support corresponding to the longer span $\left(L_{2}\right)$ to complement the information for a full assessment of the shear force in each span of the beam. To obtain the strain variation in steel stirrups and
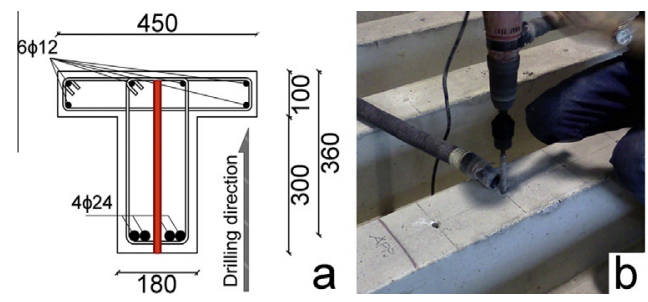
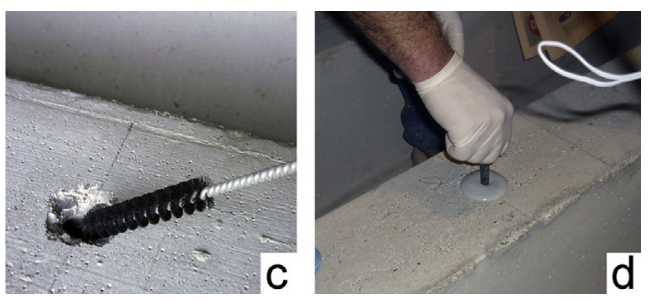

Fig. 4. Strengthening procedures for the ETS technique.

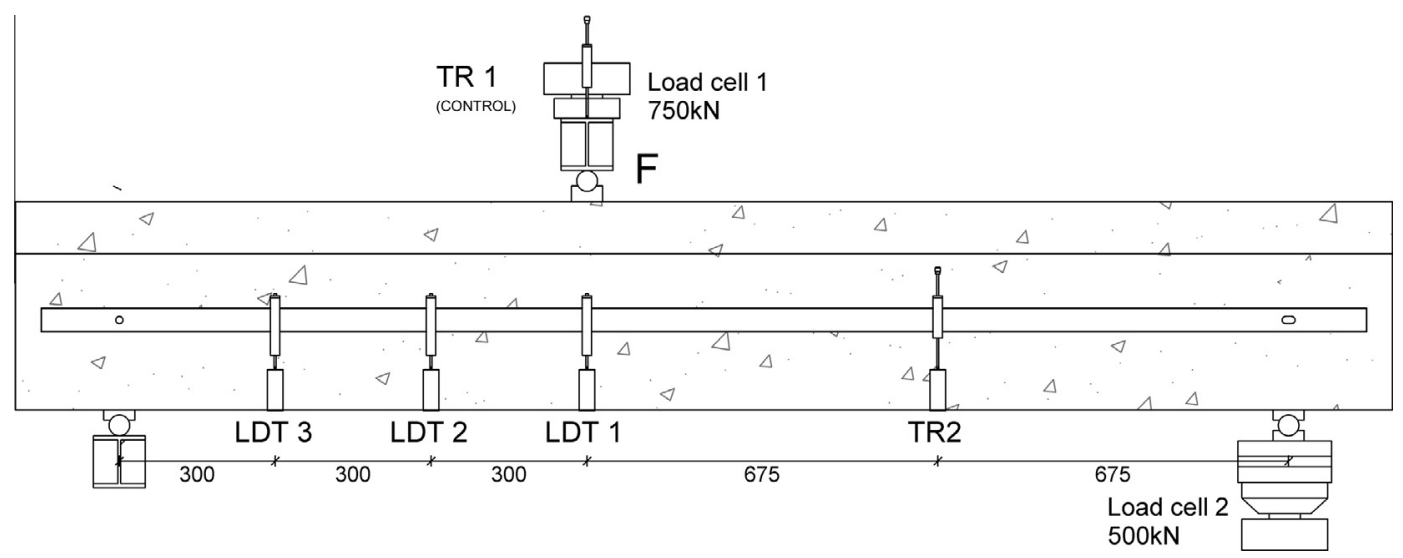

Fig. 5. Test set up (dimensions in $\mathrm{mm}$ ). 


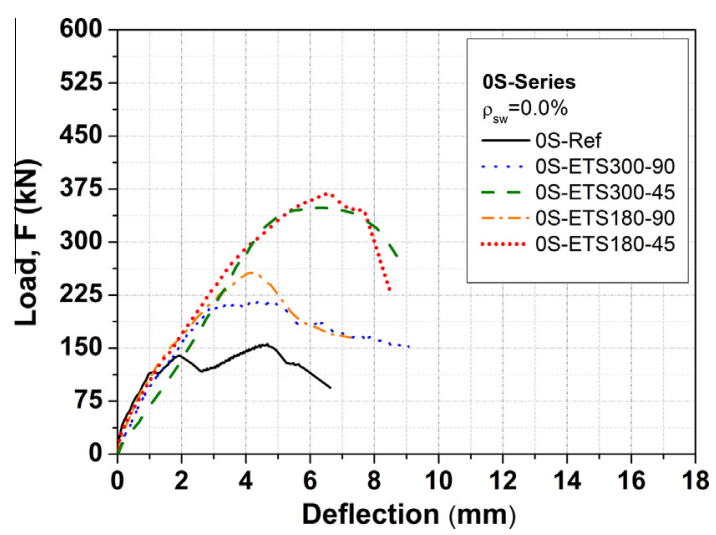

Fig. 6. Force vs. deflection at the loaded section for OS-Series.

ETS bars, electrical strain gauges (SGs) were bonded on selected cross sections of stirrups and ETS bars that have the highest probability of providing the largest contribution for the shear strengthening of the RC beam. The monitored elements are show in Fig. 3. Eight and five SGs for each beam of Series OS and 2S, respectively, were installed on ETS bars according to the configuration represented in Fig. 3c. Adopting the same principle, in each beam one steel stirrup was monitored with three SGs according to the configuration represented in Fig. 3c.

\section{Results}

\subsection{Load carrying capacity of the tested beams}

The load $(F)$-deflection $\left(u_{L S}\right)$ diagrams are presented in Figs. 6 and 7 for the two tested series. All the beams showed the same behavior up to the formation of the first diagonal crack and

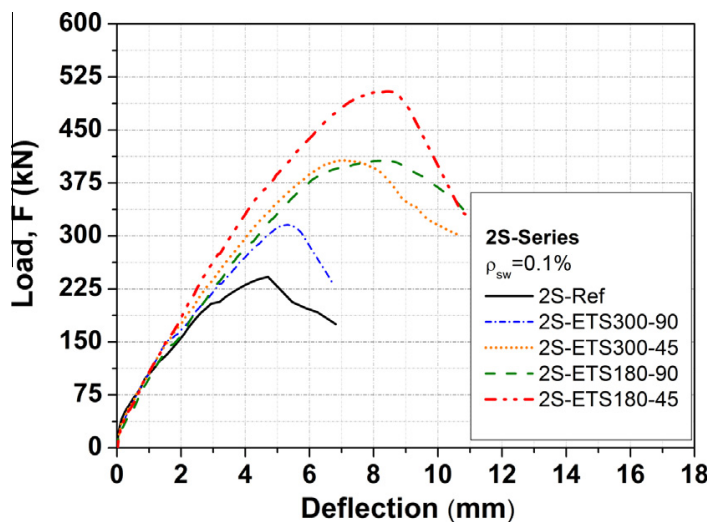

Fig. 7. Force vs. deflection at the loaded section for 2 S-Series. exhibited a shear failure mode as expected. In the reference beams the first diagonal crack occurred at a load level between 100 and $113 \mathrm{kN}$ and for a deflection $\left(u_{L S}\right)$ in the range of $0.91-0.98 \mathrm{~mm}$. As already observed in beams shear strengthened with carbon fiber reinforced polymer (CFRP) laminates installed according to the NSM technique [31], the stiffness degradation of the ETS strengthened beams is generally smaller than that of the reference beams. The ETS steel bars bridging the shear cracks surfaces offer resistance to crack opening and sliding, favoring the concrete's contribution for the shear resistance due to the aggregate interlock effect, leading to a higher load carrying capacity after shear crack initiation. This behavior is similar to the one observed in the NSM strengthened beams. The ETS strengthening technique was able to significantly increase the maximum load carrying and ultimate deflection capacities, whose performance level, measured by these two indicators, depends on the shear reinforcement arrangement. As expected all the beams exhibited a shear failure mode, since a quite high flexural reinforcement was adopted in order to avoid flexural failure mode.

The main results of the experimental tests are presented in Table 2, where $F_{\max }$ is the maximum load attained by the beams and $u_{L S \max }$ is the displacement in the loaded section at $F_{\max }$. The efficiency of the ETS technique can be evaluated by considering the $\Delta F_{\max } / F_{R \max }$ ratio, where $F_{R \max }$ is the maximum load of the reference beam, and $\Delta F_{\max }=F_{\max }-F_{R \max }$ is the increase of maximum load provided by each ETS arrangement. Table 2 also includes the maximum shear force $V_{\max }\left(=0.6 F_{\max }\right)$ applied in the $L_{1}$ beam's span (Fig. 1) and the resisting shear force provided by the ETS arrangement, $V_{f(\exp )}$. This last term was determined by considering the shear resistance in the $0 \mathrm{~S}$-Ref and $2 \mathrm{~S}$-Ref reference beams and by assuming as valid the principle that the shear resistance of a beam reinforced with steel stirrups and strengthened with ETS bars is the sum of the contributions of the concrete, steel stirrups and ETS bars. The last two columns in this table include, respectively, the tangent $\left(\mathrm{CDC}_{\text {tang }}\right)$ and the average $\left(\mathrm{CDC}_{a v g}\right)$ inclination of the failure shear crack (CDC), whose evaluation process is schematically represented in Fig. 8, for OS-Ref beam. The evaluation of the $\mathrm{CDC}_{\text {tang }}$ employed, firstly, an auxiliary horizontal line halving the distance from the longitudinal reinforcement to the bottom surface of the beam's flange ( $d_{1}$ represented in 0S-Ref beam in Fig. 8); then the point of its interception with the $\mathrm{CDC}$ was determined. The $\mathrm{CDC}_{\text {tang }}$ is the inclination of the $C D C$ at this point of interception. The $\left(\mathrm{CDC}_{a v g}\right)$ is determined by connecting the points of the interception of the CDC with the bottom surface of the beam's flange and the longitudinal reinforcement. According to the results, the $\mathrm{CDC}_{\text {tang }}$ is higher than $\mathrm{CDC}_{a v g}$, with $\mathrm{CDC}_{\text {tang }}$ values that are generally higher than $45^{\circ}$, especially in the $2 \mathrm{~S}$ series, while an average value of $43^{\circ}$ was obtained for $\mathrm{CDC}_{a v g}$ in both series.

The crack patterns at failure (see Fig. 8), shows that the number of diagonal cracks increased with the percentage of transverse steel reinforcement. The cracks started due to flexural effect achieved by crossing almost orthogonally the flexural reinforcement; however

Table 2

Experimental results of $0 \mathrm{~S}$ - and $2 \mathrm{~S}$-Series.

\begin{tabular}{|c|c|c|c|c|c|c|c|}
\hline & $F_{\max }(\mathrm{kN})$ & $u_{\text {LSmax }}(\mathrm{mm})$ & $\Delta F_{\max } / F_{R \max }(\%)$ & $V_{\max }(\mathrm{kN})$ & $V_{f(\exp )}(\mathrm{kN})$ & $\mathrm{CDC}_{\text {tang }}\left(^{\circ}\right)$ & $\mathrm{CDC}_{a v g}\left(^{\circ}\right)$ \\
\hline OS-Ref & 156.1 & 4.66 & - & 93.6 & - & 34 & 39 \\
\hline 0S-ETS300-90 & 217.8 & 4.37 & 39.5 & 130.7 & 37.0 & 48 & 42 \\
\hline 0S-ETS300-45 & 348.6 & & 123.4 & 209.2 & 115.5 & 58 & 47 \\
\hline 0S-ETS180-90 & 256.8 & 4.31 & 64.6 & 154.1 & 60.5 & 63 & 44 \\
\hline 0S-ETS180-45 & 368.8 & 6.56 & 136.3 & 221.3 & 127.7 & 35 & 43 \\
\hline 2S-Ref & 242.1 & 4.70 & - & 145.2 & - & 45 & 39 \\
\hline 2S-ETS300-90 & 315.7 & 5.32 & 30.4 & 189.4 & 44.2 & 58 & 42 \\
\hline 2S-ETS300-45 & 407.1 & 7.03 & 68.2 & 244.3 & 99.0 & 48 & 39 \\
\hline 2S-ETS180-90 & 406.8 & 8.27 & 68.1 & 244.1 & 98.8 & 73 & 47 \\
\hline 2S-ETS180-45 & 504.7 & 8.37 & 108.5 & 302.8 & 157.6 & 70 & 49 \\
\hline
\end{tabular}




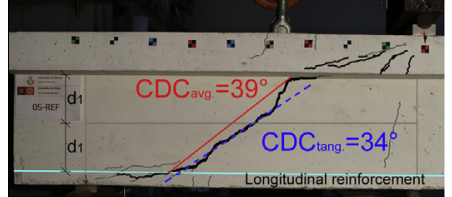
OS-Ref

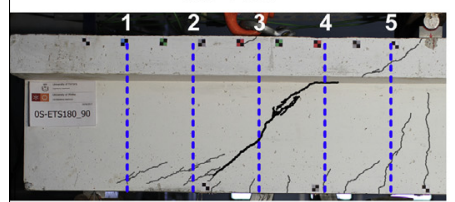

OS-ETS180-90

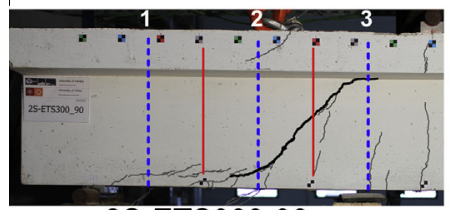

2S-ETS300-90

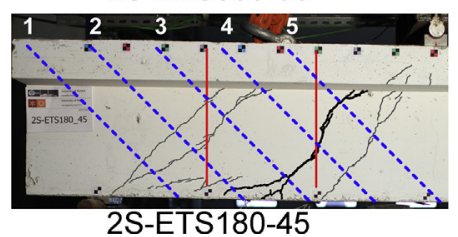

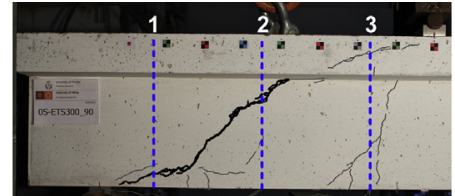

0S-ETS300-90

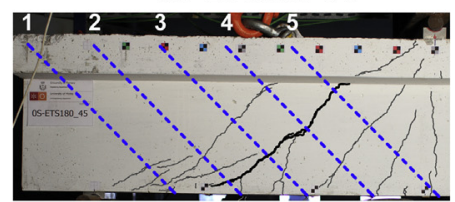

OS-ETS180-45

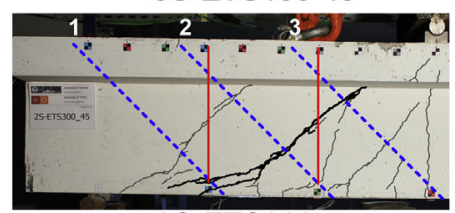

2S-ETS300-45

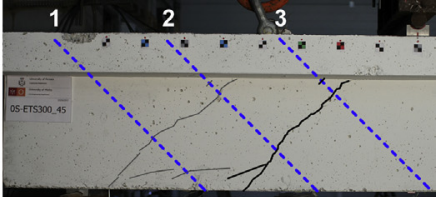

OS-ETS300-45

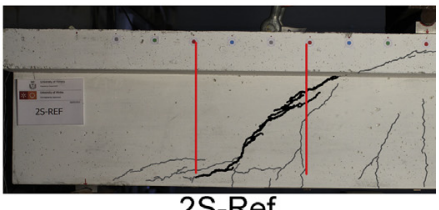

2S-Ref

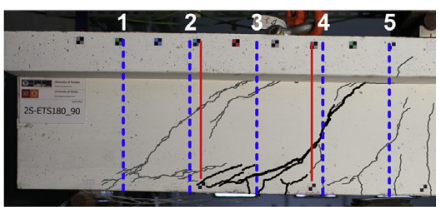

2S-ETS180-90

Fig. 8. Crack pattern of $0 S-$ and $2 S-S e r i e s$ at maximum load (— steel stirrups; ---. ETS reinforcement).

due to the tension stiffening effect the cracks' width remained of minor dimension. During the loading process of the beams, some of these cracks propagated toward the bottom surface of the flange with the average and tangent inclinations reported previously; meanwhile a diffuse pattern of shear cracks of very small inclination formed and propagated at the top level of the longitudinal reinforcement due to this reinforcement's high dowel resistance.

The load vs. deflection relationship of the beams of 0S-Series is represented in Fig. 6. The load-displacement relationship of the reference beam (OS-Ref) presented two peaks. The first peak, corresponding to a load level of $F=139.2 \mathrm{kN}\left(u_{L S}=1.92 \mathrm{~mm}\right)$, occurred when the main shear crack in the beam's web was formed; it was followed by a small load decay. This shear crack then progressed at the interface web/flange of the beam and through the web, with an increase of the load carrying capacity up to $F=156.1 \mathrm{kN} \quad\left(u_{F \max }=4.66 \mathrm{~mm}\right)$, before completely crossing the beam's web with an abrupt failure. In the OS-Series, the application of the lowest percentage of vertical ETS bars $\left(\rho_{f w}=0.15 \%\right.$; 0SETS300-90) led to an increase in terms of load carrying capacity of $39.5 \%\left(F_{\max }=217.8 \mathrm{kN}, u_{F \max }=4.37 \mathrm{~mm}\right)$; meanwhile in the highest percentage of vertical ETS bars $\left(\rho_{f w}=0.24 \%\right.$; 0S-ETS180$90)$ this increase was $64.6 \%\left(F_{\max }=256.8 \mathrm{kN}, u_{\text {Fmax }}=4.31 \mathrm{~mm}\right)$. For the ETS bars applied with an inclination of $45^{\circ}$ with respect to the beam's axis, the increase of maximum load was even higher: $123.4 \%\left(F_{\max }=348.6 \mathrm{kN}\right)$ in 0S-ETS300-45 beam of $\rho_{f w}=0.21 \%$; $136.3 \%\left(F_{\max }=368.8 \mathrm{kN}\right)$ in 0 -ETS180-45 of $\rho_{f w}=0.34 \%$. The increase of maximum deflection in this last beam was also notable $\left(u_{\text {Fmax }}=6.56 \mathrm{~mm}\right)$. With a force-deflection stiffness slightly lower than the other beams of OS-Series, the 0S-ETS300-45 beam was subjected to preliminary load cycles to overcome some test setup inaccuracies, which had partially pre-cracked this beam, leading to a reduction of initial stiffness of about $15 \%$.

The load vs. deflection relationship of the beams of 2S-Series is represented in Fig. 7. This series is characterized by 2 -arms $\phi 6$ existing steel stirrups @300 mm $\left(\rho_{w s}=0.10 \%\right)$. For the ETS vertical bars, the beams with the lowest $\left(\rho_{f w}=0.15 \%\right.$; 2S-ETS300-90) and the highest $\left(\rho_{f w}=0.24 \%\right.$; 2S-ETS180-90) percentage of ETS bars presented an increase of load carrying capacity of $30.4 \%$ $\left(F_{\max }=315.7 \mathrm{kN}, u_{F_{\max }}=5.32 \mathrm{~mm}\right)$ and $68.1 \%\left(F_{\max }=406.8 \mathrm{kN}\right.$, $u_{\text {Fmax }} 8.27 \mathrm{~mm}$ ) respectively. A higher increase of load carrying capacity was obtained for the ETS bars inclined at $45^{\circ}$. The beams with the lowest $\rho_{f w}=0.24 \%$ (2S-ETS300-45) and the highest $\rho_{f w}=0.34 \%$ (2S-ETS180-45) presented an increase of load carrying capacity of $68.2 \%\left(F_{\max }=407.1 \mathrm{kN} u_{F \max }=7.03 \mathrm{~mm}\right)$ and $108.5 \%$ $\left(F_{\max }=504.7 \mathrm{kN} u_{\text {Fmax }}=8.37 \mathrm{~mm}\right.$ ) respectively.

From the obtained experimental results, presented in Figs. 6 and 7 and Table 2, the following remarks can be pointed out: (i) The use of ETS steel bars for shear strengthening, regardless of their orientation, provided a significant increase of the load carrying capacity of the tested RC beams. The maximum increase of load carrying capacity obtained for vertical ETS bars was $64.6 \%$ and $68.1 \%$ for 0 S-Series and $2 S$-Series respectively, while for inclined ETS bars was $136.3 \%$ and $108.5 \%$ for 0 -Series and 2 S-Series, respectively. (ii) The ETS strengthening effectiveness was also significant in terms of ultimate deflection (deflection at peak load). The ultimate deflection increased up to a maximum of $40 \%$ and $78 \%$ for 0S- and $2 \mathrm{~S}$-Series, respectively.

\subsection{Strains in the ETS bars and steel stirrups}

Selected force-strain relationships of the monitored ETS bars and monitored stirrups are shown in Fig. 9, and the relevant results are presented in Table 3. In this table, $F_{\varepsilon y}$ is the force at which the shear reinforcement reached the yield initiation (based on strain measurements); $\varepsilon_{F \max }$ is the strain measured at $F_{\max }$; and $\varepsilon_{\max }$ is the maximum strain recorded in the ETS bars. For this last parameter the value of the $u_{L S} / u_{L S \max }$ ratio is also provided in order to indicate if $\varepsilon_{\max }$ occurred in the pre- $\left(u_{L S} / u_{L S \max }<1\right)$ or post-peak $\left(u_{L S} / u_{L S \max }>1\right)$ phase of the beam's response. The evaluation of the $F_{\varepsilon y}$ took into account the yield strain values determined experimentally in coupons of $\phi 6$ stirrups and $\phi 10$ steel ETS bars, respectively, $\varepsilon_{s y}=0.287 \%$ and $\varepsilon_{s y}=0.275 \%$. In Table 3 the designation attributed to the strain gauges (second column), and ETS bars and steel stirrups (third column) are represented in Figs. 8 and 9 


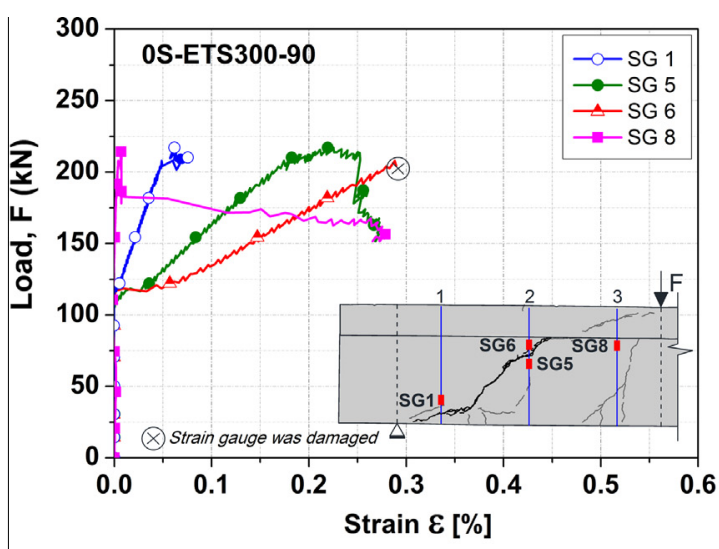

(a)

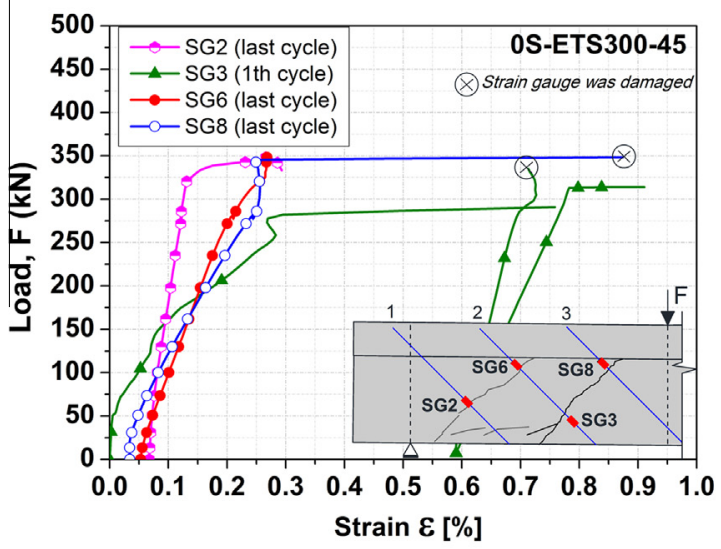

(c)

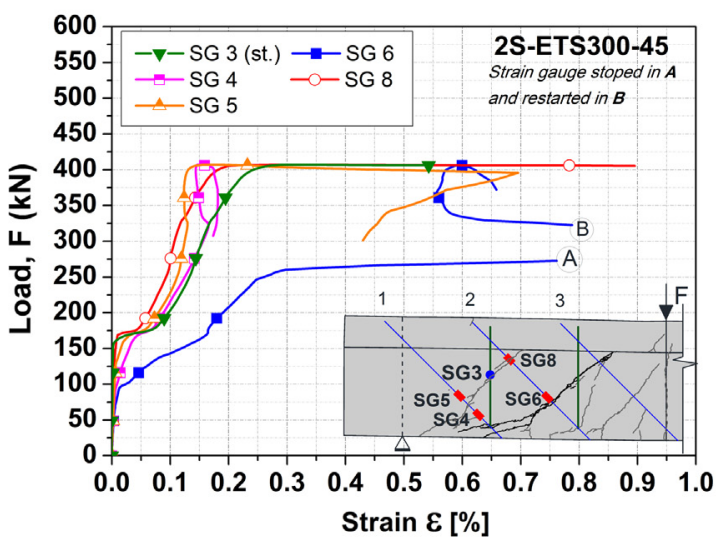

(e)

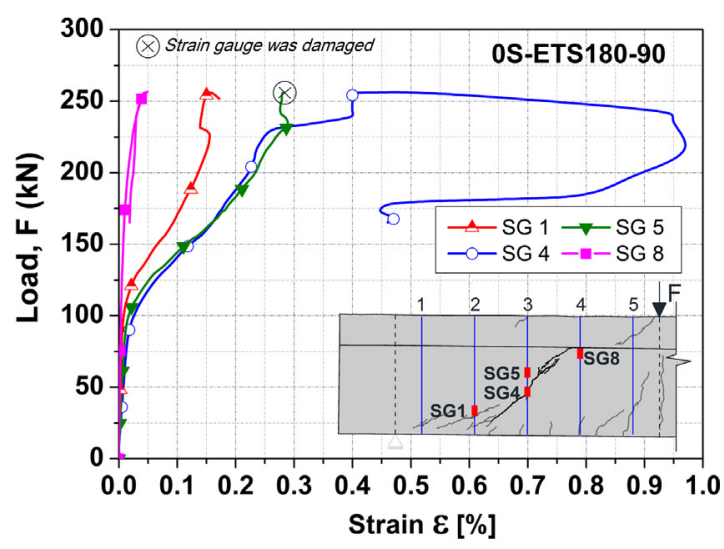

(b)

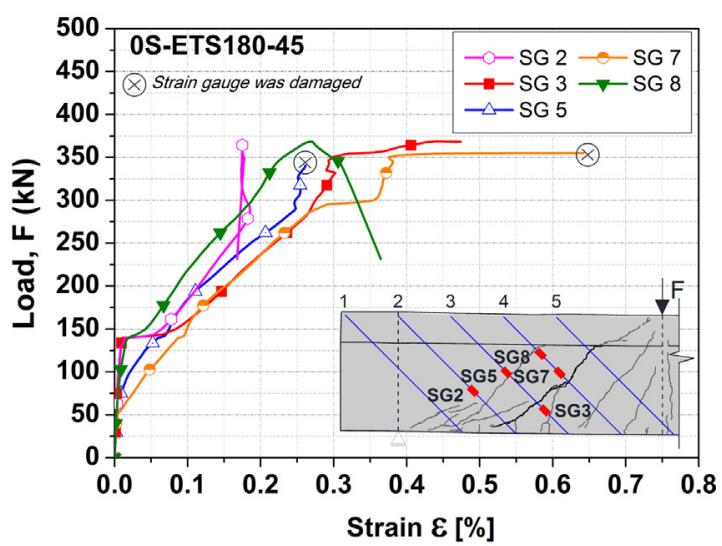

(d)

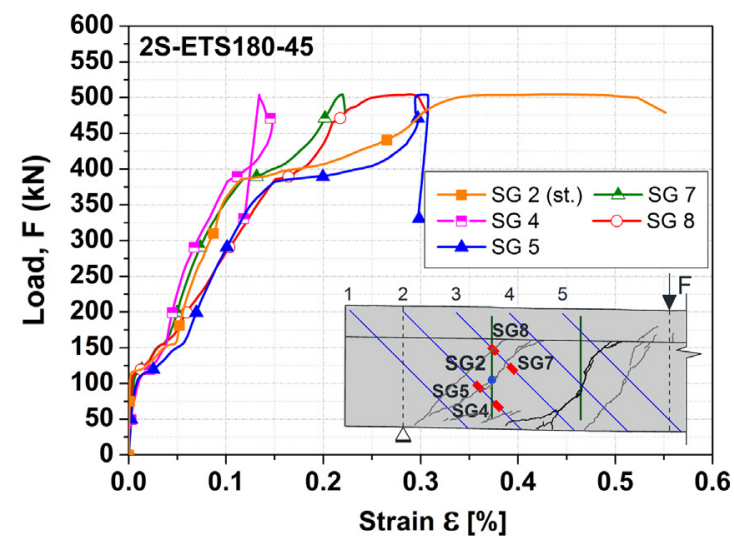

(f)

Fig. 9. Load vs. strains recorded in strain gauges applied in ETS bars and steel stirrups.

for a clearer interpretation of the results which take into account the relative position between the SGs and the shear cracks. The strain values are quite dependent on the distance of the SG from the shear failure crack. For instance, the largest strain value was recorded in the SG4 of the OS-ETS180-90 beam (1.06\%) because this SG was installed in a zone of the ETS bar crossed by the shear failure crack (Fig. 9b). The same tendency was also observed in steel stirrups: see for instance steel stirrup St1 in 2S-ETS180-90 where a maximum strain of $1 \%$ was obtained because this SG was quite close to the section of the steel stirrup crossed by a shear crack (Fig. 8).
In terms of $\varepsilon_{\max }$, the obtained values indicate that, in the strengthened beams the ETS bars and steel stirrups yielded. The yield initiation process was reflected in the propagation of the crack pattern. The yield initiation occurred for a deflection percentage of $u_{L S \max }$ that varied between 63\% (2S-ETS300-45) and $223 \%$ (OS-ETS180-90), with a tendency to occur close to the deflection at peak load. The load at yield initiation $\left(F_{\varepsilon y}\right)$ varied between $63 \%$ and $99 \%$ of the $F_{\max }$. The minimum values of the $F_{\varepsilon y} / F_{\max }$ occurred in the series with ETS bars at $45^{\circ}$, which are the beams that presented the highest strengthening efficacy. As the average inclination of the shear failure crack was about $45^{\circ}$, the favorable 
Table 3

Relevant data in terms of strains measured in 0S- and 2S-Series.

\begin{tabular}{|c|c|c|c|c|c|}
\hline Beam ID| & SG & Element & $F_{\varepsilon y[\mathrm{kN}]}\left(F_{\varepsilon y \mid} F_{\max )}(\%)\right.$ & $\varepsilon_{\text {Fmax }}(\%)$ & $\varepsilon_{\max }[\%]\left(u_{L S} / u_{L S \max }\right)$ \\
\hline \multirow[t]{4}{*}{ 0S-ETS300-90 } & 1 & Ets1 & - & 0.06 & $0.08(0.72)$ \\
\hline & 5 & Ets2 & - & 0.22 & $0.27(2.06)$ \\
\hline & 6 & Ets2 & $203(93)$ & - & $0.29(0.66)$ \\
\hline & 8 & Ets3 & - & 0.01 & $0.27(2.07)$ \\
\hline \multirow[t]{4}{*}{ OS-ETS300-45 } & 2 & Ets1 & - & 0.26 & $0.29(1.18)$ \\
\hline & 3 & Ets2 & $280.35(80)$ & - & $0.92(0.62)$ \\
\hline & 6 & Ets2 & - & 0.27 & $0.27(1.00)$ \\
\hline & 8 & Ets3 & $345.6(99)$ & - & $0.87(0.99)$ \\
\hline \multirow[t]{4}{*}{ 0S-ETS180-90 } & 1 & Ets2 & - & 0.16 & $0.17(1.03)$ \\
\hline & 4 & Ets3 & $232(90)$ & 0.59 & $1.06(2.23)$ \\
\hline & 5 & Ets3 & $227(89)$ & 0.28 & $0.29(0.99)$ \\
\hline & 8 & Ets4 & - & 0.05 & $0.05(1.00)$ \\
\hline \multirow[t]{5}{*}{ OS-ETS180-45 } & 2 & Ets2 & - & 0.18 & $0.19(0.59)$ \\
\hline & 3 & Ets3 & $299.9(81)$ & 0.46 & $0.48(1.03)$ \\
\hline & 5 & Ets3 & - & - & $0.26(0.81)$ \\
\hline & 7 & Ets4 & $289.3(78)$ & - & $0.64(0.89)$ \\
\hline & 8 & Ets4 & - & 0.27 & $0.36(1.29)$ \\
\hline 2S-Ref & 1 & St1 & - & 0.17 & $0.21(1.49)$ \\
\hline 2S-ETS300-90 & 1 & St1 & - & 0.14 & $0.19(1.26)$ \\
\hline \multirow[t]{5}{*}{ 2S-ETS300-45 } & 3 & St1 & $406.8(99)$ & 0.30 & 0.95 (1.07) \\
\hline & 4 & Ets1 & - & 0.15 & $0.18(1.24)$ \\
\hline & 5 & Ets1 & - & 0.16 & $0.73(1.14)$ \\
\hline & 6 & Ets2 & $254.8(63)$ & 0.59 & $0.84(0.63)$ \\
\hline & 8 & Ets2 & 407.0 (99) & 0.30 & $0.92(1.06)$ \\
\hline \multirow[t]{3}{*}{ 2S-ETS180-90 } & 3 & St1 & $332.3(82)$ & - & $1.00(0.83)$ \\
\hline & 5 & Ets2 & - & 0.13 & $0.14(1.32)$ \\
\hline & 8 & Ets3 & - & 0.20 & $0.20(1.00)$ \\
\hline \multirow[t]{5}{*}{ 2S-ETS180-45 } & 2 & St1 & $450(89)$ & 0.42 & $0.56(1.13)$ \\
\hline & 4 & Ets2 & - & 0.13 & $0.15(0.78)$ \\
\hline & 5 & Ets2 & $424.0(84)$ & 0.30 & $0.31(1.07)$ \\
\hline & 7 & Ets3 & - & 0.21 & $0.22(1.00)$ \\
\hline & 8 & Ets3 & 503.5 (99) & 0.29 & $0.31(1.11)$ \\
\hline
\end{tabular}

orientation of the inclined ETS bars, together with the largest effective bond length this orientation provides to these bars, led to a better mobilization of the bars' reinforcement capacity.

\subsection{Failure modes of ETS bars}

After the strengthened beams were tested, inspections on the failure modes of ETS steel bars revealed the tendency of debonding at the bar/adhesive interface (Fig. 10a). The stiff steel ribs of the ETS bars scratched the surrounding epoxy adhesive (Fig. 10b) but, as indicated in the previous section, the bond conditions were capable of mobilizing the yield strain of the ETS steel bars. This type of failure mode might justify the relatively low maximum strains recorded in the ETS bars, especially regarding those applied in a vertical direction. These strain values are lower compared to the ones obtained when using composites materials applied according to the NSM technique $[11,18]$. The average direction of the shear failure crack varied between $39^{\circ}$ and $45^{\circ}$ with regard to the beam's axis (Table 2); so during the opening and sliding process of this type of cracks, the vertical and inclined ETS bars crossing the cracks underwent axial and transversal force components. As previous studies demonstrate [32], due to this latter component the axial force transferred from the bar to the surrounding material increases, leading the ETS bars steel ribs to scratch the surrounding epoxy adhesive. Due to the higher confinement to the ETS bars assured by the web flange under compression, debonding - which was the governing failure mode - occurred in the bond length of ETS bars localized in the bottom part of the beam's cross section (apart OS-ETS30090 ). The type of failures modes reported by [33] for the NSM, (i) concrete fracture, (ii) mixed-concrete-fracture-debonding, (iii) and rupture of the shear reinforcement, were not observed in the present experimental program. Due to higher confinement conditions of

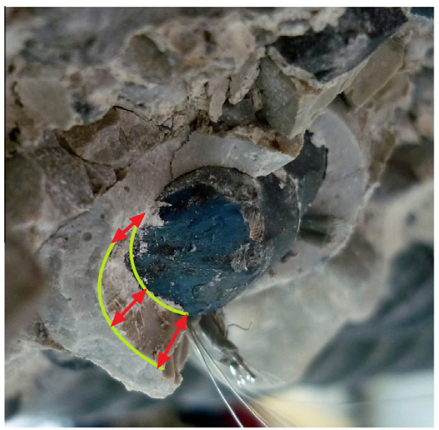

(a)

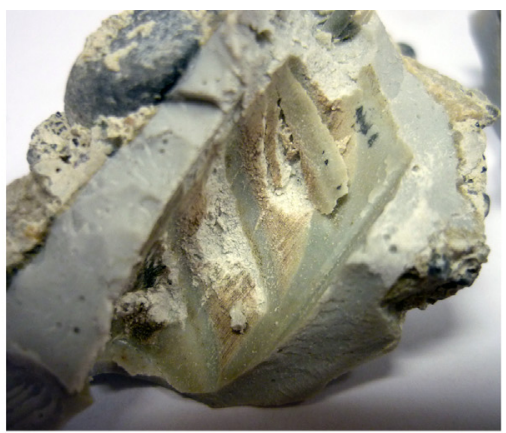

(b)

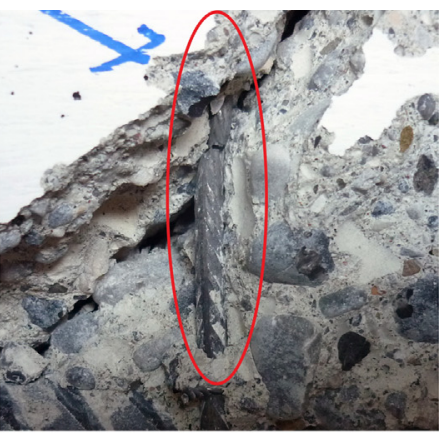

(c)

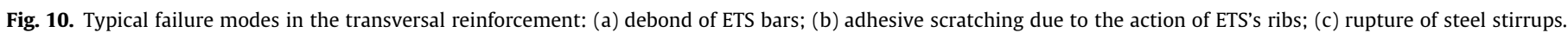


the surrounding concrete in the ETS technique, concrete fracture was not observed. Due to the scratching of the epoxy adhesive, the maximum strain recorded in the ETS bars never attained the ultimate strain of the steel, therefore rupture of ETS bars never occurred either. However, in case of the steel stirrups, due to the excellent anchorage conditions provided by its closed format, the rupture of these reinforcements was observed in some beams like 2S-ETS300-45 (Fig. 10c). It is also possible to observe that the group effect, i.e. the tendency for the detachment of the concrete cover with the increase of the shear strengthening percentage, observed when using the NSM technique [11,31,34], did not occur when the ETS technique was employed.

\section{Influence of the percentage and inclination of the ETS strengthening}

Fig. 11 represents the influence of the inclination and percentage of ETS bars on strengthening efficacy. This is evaluated by considering the $\Delta F_{\max } / F_{R \max }$ ratio (see also Table 2). This figure clearly shows that inclined ETS bars are much more effective than vertical ones, and this difference is more pronounced when beams do not include steel stirrups. The higher effectiveness of ETS inclined bars is justified by the larger total resisting bond length of the ETS bars and by more effective orientation of these bars since they cross the shear crack plane almost orthogonally (see also Fig. 8). Some inclined ETS bars were crossed by more than one diagonal shear crack. At these intersection points maximum strain levels that exceed the yield strain were recorded (for instance 2S-ETS300-45 beam, ETS2, SG6 and SG8, Table 3 and Fig. 9e), which is a demonstration of the strengthening effectiveness. For series $0 \mathrm{~S}$, and in terms of $\Delta F_{\max } / F_{R \max }$, the inclined ETS bars were 3.1 times more effective than vertical bars in ETS300 and 2.1 times in ETS180. In series $2 \mathrm{~S}$ this relative efficiency was 2.2 in ETS300 and 1.6 in ETS180. This graph also demonstrates that the ETS strengthening efficacy increases with the percentage of ETS bars, but the effectiveness of using inclined bars is much higher than increasing the percentage of ETS vertical bars. This can be justified by the much higher resisting bond length when adopting inclined bars (that are almost orthogonal to the critical shear crack) rather than increasing the number of vertical ETS bars. Even if ETS180-90 beams (vertical ETS bars spaced at $180 \mathrm{~mm}$ ) have larger $\rho_{f w}$ than ETS300-45 beams (inclined ETS bars spaced at $300 \mathrm{~mm}$ ) in both series, the latter beams presented greater strengthening effectiveness, mainly in series without steel stirrups.

\section{Influence of the existing shear reinforcement on the ETS strengthening effectiveness}

Fig. 12 represents the influence of existing steel stirrups in terms of ETS shear strengthening efficacy, evaluated by considering

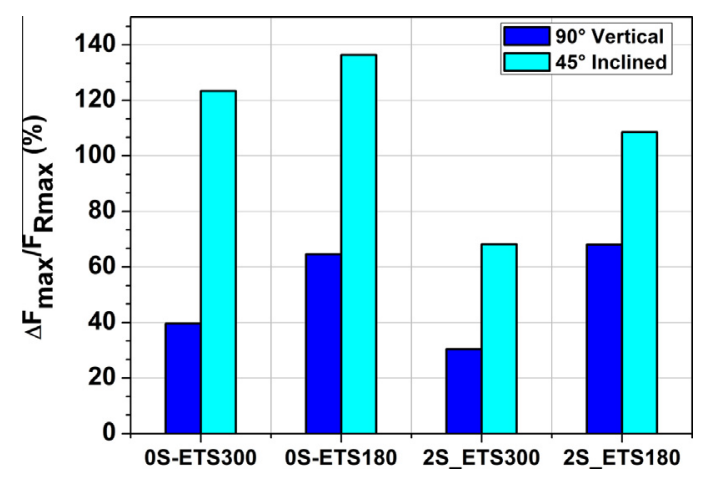

Fig. 11. Influence of the inclination and percentage of ETS bars on the ETS strengthening effectiveness. the $\Delta F_{\text {max }} / F_{R \max }$ parameter (see also Table 2). This figure shows that the amount of existing steel stirrups plays a very important role on the effectiveness of the ETS strengthening technique. As already demonstrated in beams strengthened via ETS [18,24], EBR and NSM [35-37] techniques, the effectiveness of the strengthening increases in an inverse ratio to the percentage of $\rho_{s w}$. The reasons for this detrimental effect were recently discussed, and a correction factor was proposed to account this effect [38].

According to the results obtained in the present experimental program, the presence of stirrups ( $\rho_{s w}=0.1 \%$ in the $L_{1}$ beam's span) decreased the effectiveness of the ETS technique, especially in the beams with lower $\rho_{f w}$ (-23\% in ETS300-90, and $-45 \%$ in ETS30045). In the series with higher $\rho_{f w}$, the presence of stirrups decreased the ETS strengthening effectiveness in ETS180-45 (inclined ETS bars) by 20\%, but in ETS180-90 beams the detrimental effect of existing stirrups did not occur. Fig. 8 shows that in the 2S-ETS180-90 beam two diagonal shear cracks were formed, and both were crossed by one stirrup and an ETS bar, which contributed to a significant increase of the ultimate load in this beam.

Fig. 13 compares the shear strengthening efficiency of the ETS technique with the ones obtained in the NSM and EBR techniques in a previous experimental program [35], where similar RC beams were used. The greater strengthening efficiency of the ETS technique is immediately apparent, especially when using inclined ETS bars. Taking into account the flexural capacity of the tested beams, and considering the level of strengthening effectiveness possible to obtain with the ETS technique, it can be concluded that shear brittle failure modes can be converted into ductile flexural failure modes via this technique, even in beams with relatively high flexural reinforcement ratios.

\section{Assessment of the applicability of the formulation of ACI 440 and 318 to predict the shear contribution of ETS bars}

To evaluate the nominal shear resistance of the tested beams, $V_{n}$, the recommendations of the ACI 440 [39] were adopted by assuming that ETS bars can be regarded like an FRP system from the strengthening point of view. Therefore, it is assumed:

$\phi V_{n}=\phi\left(V_{c}+V_{s}+\psi_{f} V_{f}\right)$

where $V_{c}, V_{s}$ and $V_{f}$ is the contribution of the concrete, steel stirrups and ETS bars, respectively, $\psi_{f}$ is a reduction factor applied to the contribution of the shear strengthening system, and $\phi$ is the strength reduction factor required by ACI 318 [40] which, for shear strengthening of concrete elements, assumes a value of 0.85 . As ETS bars have, in general, exceeded the steel yielding strain, this work assumes a $\psi_{f}$ value of 0.95 , typical of FRP systems applied to guarantee full wrapping conditions for the section [24]. The concrete contribution, $V_{c}$, is estimated according to the formulation

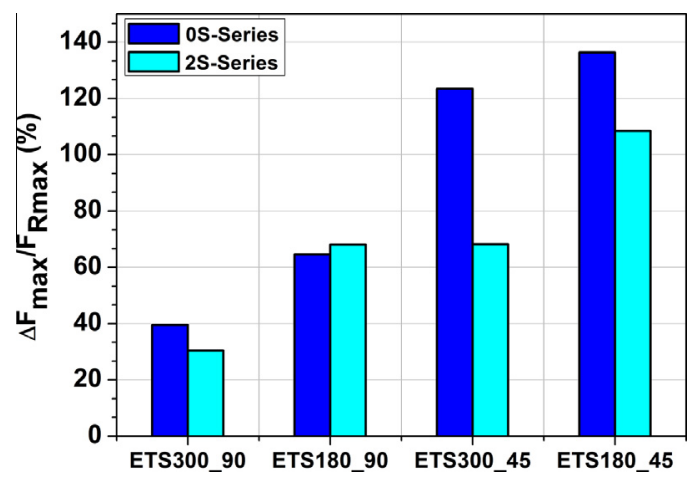

Fig. 12. Influence of existing steel stirrups on the effectiveness of the ETS technique. 


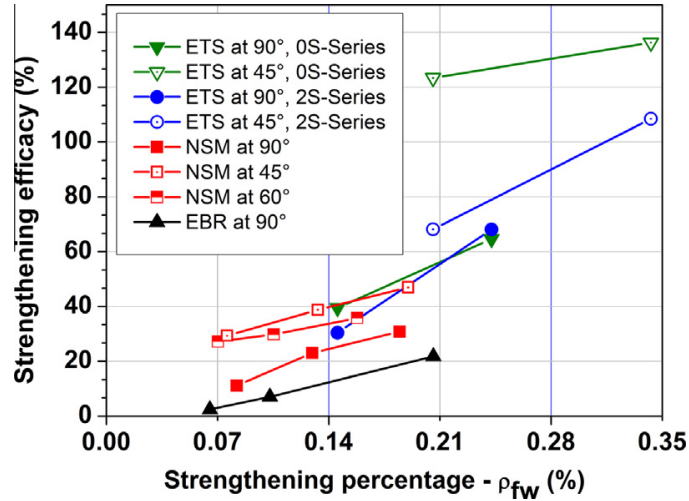

Fig. 13. Comparison of shear strengthening efficiency between ETS, NSM and EBR techniques [33].

presented in ACI 318 [40], where the parameter 0.23 in Eq. (2) is the average value of the interval proposed in section 11.2.2.1 of this design standard.

$V_{c}=0.23 \sqrt{f_{c}^{\prime}} b_{w} d \quad[$ in $\mathrm{kN}]$

where $f_{c}^{\prime}$ is the concrete cylinder compressive strength, $b_{w}$ is the web width, and $d$ is the distance from the extreme compression fiber of the cross-section to the centroid of the longitudinal reinforcement. By considering the average compressive strength of the tested beams, a value of $V_{c}=81.7 \mathrm{kN}$ is obtained. The contribution of the vertical steel stirrups was computed according to section 11.4.7.2 of the ACI 318 Code, by applying the following equation:

$V_{s}=\frac{A_{s w} f_{y s} d}{S_{s w}} \quad[$ in $\mathrm{kN}]$

where $A_{s w}$ is the cross-sectional area of a steel stirrup that has a yield stress of $f_{y s}$, with steel stirrups spaced at $s_{s w}$. The value of $V_{s}$ is $39.2 \mathrm{kN}$ for $2 \mathrm{~S}$-Series. For the evaluation of the ETS bars contribution the following general equation was adopted:

$V_{f}=\frac{A_{f w} f_{y t}(\sin \alpha+\cos \alpha) d}{s_{f w}} \quad[$ in $\mathrm{kN}]$

where $A_{f w}$ is the cross-sectional area of a ETS bar that has a yield stress of $f_{y t}$. The ETS bars are spaced at $s_{f w}$ and are inclined at $\alpha$ with respect the beam's longitudinal axis. Analytical evaluations took into account the average values of the material properties. The experimental $\left(V_{f(\exp ),} V_{n(\exp )}\right)$ and the analytical $\left(\psi_{f} V_{f}, V_{n}\right)$ results are compared in Table 4, and the ratio $k=V_{n(\exp )} / V_{n}$ is also indicated. It is worth noting that the analytical model underestimates the experimental values of $V_{n}$, mainly in series $2 \mathrm{~S}$ ( $-11 \%$ for the $0 \mathrm{~S}$-Serie and $-18 \%$ for the $2 \mathrm{~S}$-Series). The results demonstrate that the difference between $V_{n(\exp )}$ and $V_{n}$ is higher in the beams with inclined ETS bars. The larger resisting bond length of the ETS bars increases the

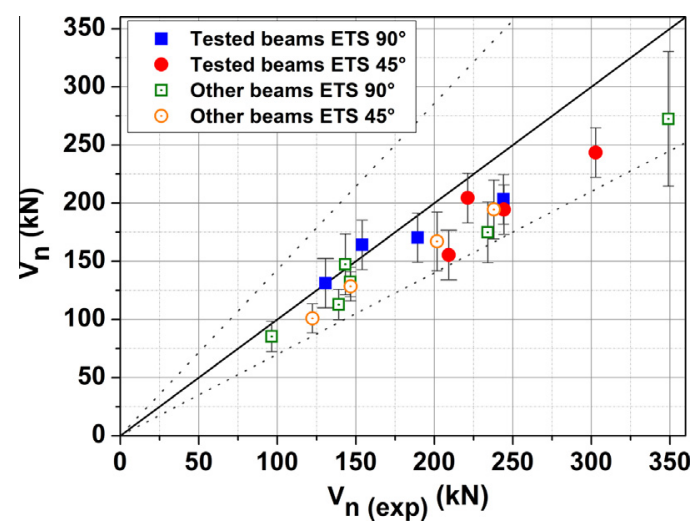

Fig. 14. Comparison between the experimental results and the analytical formulation following the ACI 318 approach.

probability that the steel yield strain is exceeded, therefore the $\psi_{f}$ factor can be considered equal to 1.0 for the contribution of these ETS bars.

The proposed formulation was also used to calculate the analytical contribution of the beams strengthened with ETS steel bars as tested by Valerio et al. and Barros and Dalfré [17,24] and failing in shear. The results are compared in Fig. 14 in terms of $V_{n(\exp )}$ and $V_{n \text { (analytical). }}$ In this figure the values of the $V_{n \text { (analytical) }}$ corresponding to the markers were obtained by using for $V_{c}$ the value of 0.23 adopted in Eq. (2); meanwhile the minimum and maximum values for the $V_{n}$ were determined by using the extreme values of 0.17 and 0.29 proposed in section 11.2.2.1 of ACI 318 for this parameter (2). Based on the results it can be concluded that this simple approach can predict, with enough accuracy for design purposes, the contribution of ETS steel bars for the shear strengthening of RC beams. As indicated in Fig. 14 the difference between the experimental and the analytical values is smaller than $30 \%$. All the predicted values of $V_{n}$ for the inclined ETS strengthened beams are underestimated by the analytical model (avg. err. $=17 \%$ ). For vertical ETS the average error is $12 \%$; one value is in this case overestimated by the model, but the error is limited to $6.5 \%$.

\section{Conclusions}

This work presents the relevant results of an experimental program carried out to evaluate the efficiency of the ETS technique for shear strengthening of RC beams. This program was prepared in order to assess the influence of following parameters on ETS effectiveness: shear reinforcement ratio of existing steel stirrups (with percentages that do not avoid shear failure occurrence), spacing (300 $\mathrm{mm}$ and $180 \mathrm{~mm}$ ) and inclination $\left(90^{\circ}\right.$ and $\left.45^{\circ}\right)$ of ETS bars. From the results the following main observations can be pointed out:

Table 4

Comparison of the experimental, $V_{f(\exp )}$, and analytical, $V_{f}$, results.

\begin{tabular}{|c|c|c|c|c|c|}
\hline Beam & $\psi_{f} V_{f}(\mathrm{kN})$ & $V_{f(\exp )}(\mathrm{kN})$ & $V_{n}(\mathrm{kN})$ & $\left.V_{n(\exp }\right)(\mathrm{kN})$ & $k=V_{n(\exp )} /\left(V_{n}\right)$ \\
\hline OS-Ref & - & - & 81.7 & 93.6 & 1.15 \\
\hline 0S-ETS300-90 & 49.5 & 37.0 & 131.1 & 130.7 & 1.00 \\
\hline OS-ETS300-45 & $70.0\left(73.6^{\mathrm{a}}\right)$ & 115.5 & $151.6\left(155.3^{\mathrm{a}}\right)$ & 209.2 & $1.38\left(1.35^{\mathrm{a}}\right)$ \\
\hline 0S-ETS180-90 & 82.4 & 60.5 & 164.1 & 154.1 & 0.94 \\
\hline OS-ETS180-45 & $116.6\left(122.7^{\mathrm{a}}\right)$ & 127.7 & $198.3\left(204.4^{\mathrm{a}}\right)$ & 221.3 & $1.12\left(1.08^{\mathrm{a}}\right)$ \\
\hline 2S-Ref & - & - & 120.8 & 145.2 & 1.20 \\
\hline 2S-ETS300-90 & 49.5 & 44.2 & 170.3 & 189.4 & 1.11 \\
\hline 2S-ETS300-45 & $70.0\left(73.6^{a}\right)$ & 99.0 & $190.8\left(194.5^{\mathrm{a}}\right)$ & 244.3 & $1.28\left(1.26^{\mathrm{a}}\right)$ \\
\hline 2S-ETS180-90 & 82.4 & 98.8 & 203.3 & 244.1 & 1.20 \\
\hline 2S-ETS180-45 & $116.6\left(122.7^{\mathrm{a}}\right)$ & 157.6 & $237.4\left(243.6^{a}\right)$ & 302.8 & $1.28\left(1.24^{\mathrm{a}}\right)$ \\
\hline
\end{tabular}

\footnotetext{
${ }^{\text {a }}$ Values calculated using $\psi_{f}=1$.
} 
1. In all the adopted strengthening solutions, a significant increase of load carrying capacity was obtained. The load carrying capacity increased more than 30\% for all the beams, and reached a maximum of $136 \%$, demonstrating that the ETS technique is an effective solution for RC beams failing in shear, adopting vertical or inclined solutions.

2. The inclined ETS bars were much more effective than vertical ones, due to the larger available resisting bond length assured in the former configuration. This effectiveness is also caused by the favorable orientation of the inclined ETS bars $\left(45^{\circ}\right)$, since the average inclination of the shear failure crack of the strengthened beams varied between $39^{\circ}$ and $45^{\circ}$ with the beam's axis, therefore the ETS bars were almost orthogonal to this crack.

3. As already observed in the NSM and EBR shear strengthening techniques with FRP systems, the strengthening effectiveness decreased with the increase of the percentage of existing steel stirrups.

4. The shear strengthening effectiveness increased with the shear strengthening ratio, and the detrimental group effect observed in EBR and NSM techniques, due to the mutual interaction of consecutive FRP shear reinforcement, did not occur in the ETS technique, even for the minimum adopted spacing of ETS bars.

5. For equal shear strengthening ratios, the ETS technique was more effective than FRP-based EBR and NSM shear strengthening techniques. The high effectiveness of the ETS technique results from the excellent bond conditions provided by the core concrete surrounding these bars, which allowed the steel yield strain to be exceeded in more than one section of the same ETS bar crossing shear cracks.

6. The level of strengthening efficiency obtained indicates the possibility of converting shear brittle failure modes in flexural ductile failure modes, even in beams of quite high flexural reinforcement ratio.

7. A model based on the $\mathrm{ACI}$ recommendations to predict the shear resistance of shear strengthened $\mathrm{RC}$ beams was able to estimate with sufficient accuracy the experimental results. In general this model predicted lower shear resistance than the one obtained experimentally, but with a safety factor in keeping with the recommendations for a shear failure problem.

Since steel bars applied into the concrete core were used, the ETS technique is more competitive than EBR and NSM techniques. It should also be remarked that corrosion can be avoided in ETS steel bars by providing a cement based cover at the bars' extremities, and these reinforcements provide much better protection in case of fire.

\section{Acknowledgements}

The authors wish to acknowledge Elletipi S.r.l. (Ferrara, Italy) for supporting the experimental program, Interbau S.r.l. (Milano, Italy) for applying the ETS strengthening system and the ENDIF Geomatic Group (University of Ferrara, Italy) for monitoring the experimental program. The authors also wish to acknowledge the Engineering Department of the University of Ferrara for its financial support.

\section{References}

[1] Bakis CE, Bank LC, Brown VL, Cosenza E, Davalos JF, Lesko JJ, et al. Fiberreinforced polymer composites for construction-state-of-the-art review. J Compos Constr 2002;6(2):73-87. http://dx.doi.org/10.1061/(ASCE)10900268(2002)6:2(73).

[2] Sena-Cruz JM, Barros JAO. Bond between near-surface mounted carbonfiber-reinforced polymer laminate strips and concrete. J Compos Constr 2004;8(6):516-27. http://dx.doi.org/10.1061/(ASCE)1090-0268(2004)8: 6(519).
[3] Barros JAO, Dias SJE, Lima JLT. Efficacy of CFRP-based techniques for the flexural and shear strengthening of concrete beams. Cem Concr Compos 2007;29(3):203-17. http://dx.doi.org/10.1016/i.cemconcomp.2006.09.001.

[4] Bilotta A, Ceroni F, Di Ludovico M, Nigro E, Pecce M, Manfredi G. Bond efficiency of EBR and NSM FRP systems for strengthening concrete members. J Compos Constr 2011;15(5):757-72. http://dx.doi.org/10.1061/(ASCE)CC.1943$\underline{5614.0000204}$

[5] Seo S, Feo L, Hui D. Bond strength of near surface-mounted FRP plate for retrofit of concrete structures. Compos Struct 2013;95:719-27. http:// dx.doi.org/10.1016/i.compstruct.2012.08.038.

[6] De Lorenzis L, Nanni A, La Tegola A. Flexural and shear strengthening of reinforced concrete structures with near surface mounted FRP rods. In: Proc of 3rd international advanced composite materials in Bridges and Structures Ottawa, Canada. 15-18 August; 2000. p. 521-8.

[7] Carolin A, Nordin H, Täljsten B. Concrete beams strengthened with prestressed near surface mounted reinforcement (NSMR). In: Proc of international conference FRP composites in civil engineering (CICE 2001), 12-14 December 2001, Hong Kong, China; 2001.

[8] Hassan T, Rizkalla SH. Investigation of bond in concrete structures strengthened with near surface mounted carbon fiber reinforced polymer strips. J Compos Constr 2003;7(3):248-57. http://dx.doi.org/10.1061/ (ASCE) 1090-0268(2003)7:3(248).

[9] El-Hacha R, Rizkalla SH. Near-surface-mounted fiber-reinforced polymer reinforcements for flexural strengthening of concrete structures. ACI Struct J 2004;101(5):717-26. http://dx.doi.org/10.14359/13394.

[10] De Lorenzis L, Nanni A. Shear strengthening of reinforced concrete beams with near-surface mounted fiber-reinforced polymer rods. ACI Struct J 2001;98(1):60-8. http://dx.doi.org/10.14359/10147.

[11] Dias SJE, Barros JAO. Shear strengthening of RC T-section beams with low strength concrete using NSM CFRP laminates. Cem Concr Compos 2011;33(2):334-45. http://dx.doi.org/10.1016/i.cemconcomp.2010.10.002.

[12] Dias SJE, Barros JAO. NSM shear strengthening technique with CFRP laminates applied in high-strength concrete beams with or without pre-cracking. Compos Part B Eng 2012;43(2):290-301. http://dx.doi.org/10.1016/ j.compositesb.2011.09.006.

[13] Dias SJE, Barros JAO. Shear strengthening of RC beams with NSM CFRP laminates: experimental research and analytical formulation. Compos Struct 2013;99:477-90. http://dx.doi.org/10.1016/i.compstruct.2012.09.026.

[14] Anwarul Islam AKM. Effective methods of using CFRP bars in shear strengthening of concrete girders. Eng Struct 2009;31(3):709-14. http:/ dx.doi.org/10.1016/i.engstruct.2008.11.016.

[15] Rahal KN, Rumaih HA. Tests on reinforced concrete beams strengthened in shear using near surface mounted CFRP and steel bars. Eng Struct 2011;33(1):53-62. http://dx.doi.org/10.1016/j.engstruct.2010.09.017.

[16] Bianco V, Barros JAO, Monti G. New approach for modeling the contribution of NSM FRP strips for shear strengthening of RC beams. J Compos Constr 2010;14(1):36-48. http://dx.doi.org/10.1061/(ASCE)CC.1943-5614.0000048.

[17] Valerio P, Ibell TJ, Darby AP. Deep embedment of FRP for concrete shear strengthening. Proc ICE - Struct Build 2009;162(5):311-21. http://dx.doi.org/ 10.1680/stbu.2009.162.5.311.

[18] Chaallal O, Mofidi A, Benmokrane B, Neale K. Embedded through-section FRP rod method for shear strengthening of RC beams: performance and comparison with existing techniques. J Compos Constr 2011;15(3):732-42. http://dx.doi.org/10.1061/(ASCE)CC.1943-5614.0000174.

[19] Sissakis K, Sheikh SA. Strengthening concrete slabs for punching shear with carbon fiber-reinforced polymer laminates. ACI Struct J 2007;104(1):49-59. http://dx.doi.org/10.14359/18432.

[20] Fernàndez Ruiz M, Muttoni $\mathrm{A}$, Kunz J. Strengthening of flat slabs against punching shear using post-installed shear reinforcement. ACI Struct J 2010;107(4):434-42. http://dx.doi.org/10.14359/51663816.

[21] Valerio P, Ibell T, Darby A. Shear assessment and strengthening of contiguousbeam concrete bridges using FRP bars. In: Proc of the 7th international symposium on fiber reinforced polymer reinforcement for concrete structures (FRPRCS-7), Kansas City, Missouri; 6-9 November; 2005. p. 825-48.

[22] Barros JAO, Dalfré GM, Trombini E, Aprile A. Exploring the possibilities of a new technique for the shear strengthening of RC elements. In: Proc Int Conf challenges civil construction (CCC2008), Univ Porto, Porto, Portugal; 16-18 April; 2008.

[23] Mattock AH, Hawkins NM. Shear transfer in reinforced concrete recent research. PCI J 1972;2:55-75.

[24] Barros JAO, Dalfré GM. Assessment of the effectiveness of the embedded through-section technique for the shear strengthening of reinforced concrete beams. Strain 2012;49(1):75-93. http://dx.doi.org/10.1111/str.12016.

[25] Eurocode 2 design of concrete structures - Part 1-1: general rules and rules for buildings. EN 1992-1-1; 2005.

[26] Collins MP, Mitchell D. Prestressed concrete structures. Englewood Cliffs (NJ): Prentice-Hall, Inc.; 1997.

[27] European committee for standardization. EN 206-1 concrete - Part 1: specification, performance, production and conformity; 2001.

[28] C.S.L.P. Nuove Norme Tecniche per le Costruzioni DM 14 Gennaio 2008 Gazzetta Ufficiale n. 29 del 4 Febbraio 2008; 2009.

[29] European committee for standardization. UNI EN ISO 6892-1:2009 metallic materials - tensile testing - Part 1: method of test at room temperature. 2009.

[30] European committee for standardization. ISO 527-2:2012. Plastics determination of tensile properties - Part 2: test conditions for moulding and extrusion plastics; 2012. 
[31] Dias SJE, Barros JAO. Performance of reinforced concrete T beams strengthened in shear with NSM CFRP laminates. Eng Struct 2010;32(2):373-84. http:/ dx.doi.org/10.1016/i.engstruct.2009.10.001.

[32] Mazaheripour H, Barros JAO, Sena-Cruz JM, Pepe M, Martinelli E. Experimental study on bond performance of GFRP bars in self-compacting steel fiber reinforced concrete. Compos Struct 2013;95:202-12. http://dx.doi.org/ 10.1016/i.compstruct.2012.07.009.

[33] Bianco V, Monti G, Barros JA. Theoretical model and computational procedure to evaluate the NSM FRP strips shear strength contribution to a RC beam. J Struct Eng 2011;137(11):1359-72. http://dx.doi.org/10.1061/(ASCE)ST.1943541X.0000370.

[34] Rizzo A, De Lorenzis L. Behavior and capacity of RC beams strengthened in shear with NSM FRP reinforcement. Constr Build Mater 2009;23(4):1555-67. http://dx.doi.org/10.1016/j.conbuildmat.2007.08.014.

[35] Dias SJE, Barros JAO. Experimental behaviour of RC beams shear strengthened with NSM CFRP laminates. Strain 2011;48(1):88-100. http://dx.doi.org 10.1111/j.1475-1305.2010.00801.x.
[36] Bousselham A, Chaallal O. Effect of transverse steel and shear span on the performance of RC beams strengthened in shear with CFRP. Compos Part B Eng 2006;37(1):37-46. http://dx.doi.org/10.1016/i.compositesb.2005.05.012.

[37] Grande E, Imbimbo M, Rasuolo A. Effect of transverse steel on the response of RC beams strengthened in shear by FRP: experimental study. J Compos Constr 2009;13(5):405-14. http://dx.doi.org/10.1061/(ASCE)1090-0268(2009)13: 5(405).

[38] Chen GM, Teng JG, Chen JF. Shear strength model for FRP-strengthened RC beams with adverse FRP-steel interaction. J Compos Constr 2013;17(1):50-66. http://dx.doi.org/10.1061/(ASCE)CC.1943-5614.0000313.

[39] American concrete institute. Guide for the design and construction of externally bonded FRP systems for strengthening concrete structures. ACI440.2R. Farmington Hills, MI: American Concrete Institute, Detroit; 2008.

[40] ACI Committee 318. Building code requirements for structural concrete and commentary (ACI 318-08). American Concrete Institute, Detroit; 2008. 